\title{
Ações do Programa de Educação Tutorial (PET): Intervenções para prevenção do bullying
}

\author{
Cecilia Maria Resende Gonçalves de Carvalho \\ ceciliamaria.pop@hotmail.com
}

Raul Santos Silva

raul_ssilva@hotmail.com

Dheyvid Fhelipe Correia Lima Pereira

dvd9001@hotmail.com

Kelciane Mendes da Silva

kelcimendes@hotmail.com

Universidade Federal do Piauí | Brasil

\section{Resumo}

A neurociência contribui para a compressão de como o 0 texto relata a experiência vivenciada com estudantes de uma escola pública municipal de Teresina, PI, para trabalhar a temática do bullying, suas formas de prevenção, identificação e consequências. 0 trabalho foi realizado usando como método a educação problematizadora de Paulo Freire. Apesar dos estudantes perceberem práticas de agressões o assunto é pouco discutido e são vários os tabus existentes. As intervenções educativas realizadas contribuíram para sensibilizar os estudantes e demais atores sociais da escola para a adoção de práticas de relações saudáveis como forma de prevenção da violência e despertou à atenção para a criação de formas de enfrentamento dessa problemática.

\section{Palavras-chave}

Bullying. Escola. Direitos Humanos. 


\section{Introdução}

O papel da instituição escolar é contribuir para a formação integral do aluno privilegiando não apenas atividades cognitivas, mas também a realização de um trabalho educativo que auxilie o educando no desenvolvimento de uma consciência moral, de valores e normas de comportamentos que o possibilitem exercer a sua cidadania (FREIRE, 1996; CHAUI, 2003).

Com efeito, trabalhar valores nas práticas educativas é atender o que preconiza o artigo 26 da Declaração Universal dos Direitos Humanos com relação ao ensino e a educação. Certamente, os pilares que norteiam essa "declaração de direito" é o pleno desenvolvimento da personalidade humana e do fortalecimento do respeito pelos direitos humanos e liberdades fundamentais, de modo a promover a compreensão, a tolerância e a amizade entre as nações e grupos raciais ou religiosos (ONU,1948).

Nesse sentido, Piaget (1973) argumenta que o direito à educação não se restringe somente a frequentar escolas, mas também a encontrar nesse importante espaço da vida do ser humano tudo o que é necessário para a construção de um raciocínio pronto e de uma consciência moral à medida que a educação vise ao pleno desenvolvimento da personalidade. Logo, de acordo com o art. 27 da Lei de Diretrizes e Bases da Educação Nacional (LDB) os conteúdos curriculares da educação básica deverão seguir algumas diretrizes, entre as quais se destaca “a difusão de valores fundamentais ao interesse social, aos direitos e deveres dos cidadãos, de respeito ao bem comum e à ordem democrática" (BRASIL, 1996).

Apesar desse aparato legal oferecer subsídios para uma formação cidadã consoante com valores e práticas democráticas e de respeito mútuo percebe-se que, a realidade vivenciada nas instituições escolares é bastante distinta do que a lei preconiza. Não é raro ouvir/ver nos meios de comunicação notícias sobre inúmeros casos de violência nas escolas que consistem em agressões físicas e psicológicas (desrespeito, humilhações, ameaças, entre outras) que podem causar sérias consequências para suas vítimas como, por exemplo, queda no rendimento dos estudos, evasão escolar, e até mesmo, em casos mais graves, o suicídio. (FANTE, 2005). Tais práticas agressivas são denominadas de bullying, termo inglês bastante usado para designar relações desiguais de poder entre pares, no caso, entre alunos, que se caracteriza por diversificados atos de 
violência exercidos por uma pessoa ou grupo para com outra, sem motivos evidentes e de maneira contínua (MARTINEZ, 2001; FANTE, 2004).

Assim, à medida que o bullying se tornou um grave problema social o mesmo se tornou objeto de intervenção jurídica com a Lei no 13.185, sancionada em 06 de novembro de 2015. Essa lei instituiu o Programa de Combate à Intimidação Sistemática (bullying), cujo objetivo principal é a prevenção e o combate ao bullying no âmbito de toda a sociedade, além de estabelecer como dever aos estabelecimentos de ensino, clubes e agremiações recreativas a tomada de medidas de conscientização, prevenção e combate ao bullying, conforme preconizado no art. 5ํ․ da referida legislação.

Desse modo, dada a importância de tal assunto e sua recorrência nas instituições escolares com ênfase nas consequências negativas que o bullying pode ocasionar na vida tanto das vítimas como dos agressores, o grupo PET Integração da Universidade Federal do Piauí (UFPI), estudou e observou as práticas agressivas nas escolas, o que culminou com a construção do Projeto de Extensão "Bullying: em busca de igualdade e da dignidade humana". A proposta principal dessa investigação é fomentar a construção de uma cultura de respeito às diferenças proporcionando um espaço para discussão e reflexão sobre o bullying no ambiente escolar, de modo a oportunizar aos alunos trocas de experiências e um melhor convívio social. Portanto, esse trabalho tem por objetivo relatar as práticas e experiências vivenciadas durante as ações educativas desenvolvidas para os estudantes da escola municipal Noé Fortes sobre o bullying e suas formas de prevenção, identificação e consequências.

\section{Métodos}

O projeto "Bullying" surgiu no interior do grupo PET cuja ideia era criar espaços de discussão sobre essa temática na escola. Já havia uma atuação marcante do grupo em outras atividades de projetos de extensão voltadas para educação, promoção dos direitos humanos e cidadania, identificadas de acordo com a demanda e interesse da comunidade escolar.

Antes de iniciar as atividades do projeto na escola foi proposto a realização de cursos para a formação/atualização do grupo sobre a temática do bullying. Assim, no âmbito do PET, considera-se que o assunto foi amplamente discutido e o planejamento 
de todas as atividades foi realizado nas reuniões semanais, das quais participavam os bolsistas e tutor, além de outros voluntários convidados. Após aprovação do projeto na Câmara de Extensão da Pró-Reitoria de Extensão da UFPI, Campus Ministro Petrônio Portela em Teresina-P, foi firmada a parceria institucional com a direção da escola municipal Noé Fortes, situada na zona leste, bairro Planalto Ininga, em Teresina-PI. Logo a seguir, foram feitas visitas à escola para a divulgação das ações através de cartazes, contato com alunos, professores e direção, que ocorreu uma semana antes da data prevista para início do projeto. O propósito era agendar e comunicar a comunidade escolar sobre a data e horário que as ações do projeto seriam desenvolvidas.

As atividades foram conduzidas pelos bolsistas do PET dos cursos de Direito, Nutrição, Serviço Social e Pedagogia, sob a coordenação da tutora. De início, foi realizada uma dinâmica de apresentação, onde se colocou os principais objetivos do projeto e uma breve introdução teórica sobre o "bullying". A proposta foi bem aceita, e a seguir, o conteúdo passou a ser trabalho de forma mais aprofundada através de vários encontros junto aos alunos do $5^{\circ}$ ao $8^{\circ}$ ano do ensino fundamental, durante um semestre letivo, num total de 16 encontros.

Foram realizadas diversas oficinas educativas, utilizando-se de uma abordagem pedagógica problematizadora de Paulo Freire (1977), para retratar a temática sobre bullying de diversas maneiras e construir conhecimentos por meio do diálogo. Durante as oficinas, desenvolveu-se um trabalho de sensibilização como forma de acolher os participantes em suas diversidades, facilitar a interação e a troca de experiências, respeitando-se e valorizando-se as manifestações de cada um. Isso transcorreu em um clima alegre e participativo e culminou com a realização de um seminário envolvendo toda a comunidade escolar.

Como estratégia para despertar a atenção, o interesse e a adesão integral dos educandos desenvolveu-se atividades lúdicas como por exemplo, dinâmicas com músicas, vídeos, painéis, desenhos e peças teatrais. No encerramento, realizou-se uma encenação teatral, para reforçar os conhecimentos adquiridos durante as oficinas, discutir sobre as consequências do bullying e estimular o desenvolvimento de práticas de prevenção desse tipo de agressividade no ambiente escolar. 


\section{Resultados e discussão}

Os resultados alcançados com essa experiência mostram que houve uma melhora nas relações entre os alunos no ambiente escolar, expresso pela diminuição de brigas, xingamentos e mais manifestação de atitudes de cooperação no decorrer do projeto. Como retrata Antunes (2008), para trabalhar com educação é preciso participar do cotidiano da escola, construindo saberes e experiências integradas com todos que compõe o ambiente escolar.

Destaca-se que com a encenação da peça "O menino com a cicatriz no rosto", foi possível estimular os educandos a expressar suas opiniões, medos, além de favorecer uma aproximação de forma harmoniosa produzindo um resultado bastante significativo. Foi possível proporcionar diversos momentos de reflexão e sensibilização dos educandos a descoberta e a tomada de consciência de si mesmo, além de ampliar o olhar para perceber o outro de forma mais humana.

A história da peça relatava a vida de um menino chamado Alberto que possuía uma cicatriz enorme e horrível no rosto e era alvo de bullying na escola parte dos seus colegas de sala de aula. Alberto, o protagonista da história, constantemente era violentado por seus colegas com agressões físicas e verbais, deixando-o muito triste e deprimido, prejudicando dessa forma, o seu rendimento escolar já que o garoto pensava em desistir de ir à escola várias vezes. Para piorar a situação, um grupo de pais procurou o professor para reclamarem do menino e exigirem a sua expulsão da escola, pois segundo eles, Alberto com a sua feitura atrapalhava os seus filhos e os outros alunos da classe. Apesar dessa reivindicação ter piorado a vida de Alberto ela se constituiu como o ponto final para que as agressões vividas fossem cessadas, pois ao se ver intimidado e com o risco de ser expulso da escola o protagonista foi obrigado a reagir por si próprio ao contar sua história de vida e explicar o motivo pelo qual tinha uma cicatriz no rosto que o assemelhava ao "fantasma da ópera". Alberto explicou que adquiriu a cicatriz porque salvou sua irmã de um incêndio ocorrido na sua casa enquanto todos dormiam arriscando para isso sua própria vida, o menino já emocionado chorou e afirmou aos seus colegas que a sua cicatriz não diminuía o seu caráter em nada, e que sofria muito quando o desqualificavam por sua aparência apesar de todos considerarem as agressões sofridas como brincadeiras. 
Nesse sentido, a peça demostrou que muitas vezes as opressões vivenciadas passam despercebidas e não são levados a sério por parte dos seus espectadores (alunos, pais e professores da história) que não interveem por considerarem o bullying uma prática normal para comportamento de crianças e adolescentes. As práticas de bullying foram reiteradas ao longo da peça com o intuito dos alunos perceberem a injustiça que se comete com quem é vítima e fazer com que alunos se identificassem de alguma forma com aquela situação, de modo que pudessem associá-las a casos ocorridos no seu ambiente escolar.

Em seguida a apresentação da peça teatral houve um momento denominado de "desmistificação", onde cada ator saía do seu personagem e fazia uma exposição oral sobre as consequências negativas do bullying, enfatizando a melhor maneira de prevenilo, ou seja, como cada personagem deveria se comportar a fim de identificar, prevenir e evitar essa prática. Essa exposição oral promoveu um bom espaço para reflexão dos alunos e também serviu para contribuir na conscientização dos danos psicológicos que o bullying pode causar. Na sequência, foi exibido um vídeo que falava da "mulher mais feia do mundo" onde se procurou abordar o preconceito sofrido pela mulher que aparecia no vídeo e como ela se comportava diante das ofensas e rejeições. 0 objetivo da exposição do vídeo foi sensibilizar a comunidade sobre as diferenças que encobrem a espécie humana, demonstrar que existem pessoas de diversos fenótipos, levando em consideração que isso é um fator que sempre deve ser visto como normal, portanto, respeitado.

Posteriormente, foi proposto a formação de grupos de debate para discutir a temática e elaborar medidas de prevenção para as mais diversas práticas de bullying que ocorrem na escola, dentre eles o cyberbullying, que consiste em insultos pessoais, agressões físicas, isolamento social, expressões preconceituosas e exposição de fotos íntimas, apelidos, etc. (SILVA, 2010). Assim, foram formados sete grupos cada um composto por seis a sete alunos coordenados por um petiano, e a proposta consistia em cada grupo apresentar medidas de prevenção ao bullying, sendo sugerido que os grupos construíssem um painel ilustrativo com imagens e frases apresentando as principais propostas.

Após esse momento de discussão e construção das medidas de prevenção ao 
bullying, cada grupo expressou o que constatava nos cartazes e explicava o seu ponto de vista sobre as figuras escolhidas, destacava os principais aspectos relacionados com o tema e descrevia suas vivências na escola em relação à temática. Nesse momento os alunos puderam expressar seus sentimentos, emoções e como interpretavam as práticas de bullying, propondo também maneiras de enfrentá-lo.

Os estudantes se manifestaram com frases do tipo: "cyberbullying não tem graça", "internet é para se divertir, não pra insultar", " é respeitando que se é respeitado", " trate as pessoas da forma como você gostaria de ser tratado", "gentileza gera gentileza", "violência não leva a lugar nenhum”, " fazer o bem sem olhar a quem”, " palavras também machucam". Dessa forma, constatou-se que os alunos entenderam o propósito da ação de promover a igualdade e o respeito entre as pessoas como uma forma de prevenir e enfrentar o bullying e tornar o convívio de todos melhor.

Esses resultados mostram que o projeto e os métodos utilizados para trabalhar a prevenção do bullying teve efeito positivo entre os alunos, já que todos os grupos expressaram sentimentos e emoções que favorecesse e estimulasse o potencial dos alunos para a prática do bom convívio escolar e desenvolvimento da autoestima.

Observou-se que a maioria dos estudantes e, alguns professores possuíam pouca informação sobre o bullying, o que dificultava o diagnóstico e sua prevenção no âmbito escolar. Foi verificado também, durante a pesquisa a presença do bullying em vários momentos: a prática de colocar apelidos desagradáveis e pejorativos era comum, especialmente relacionados a obesidade e questões sexuais, inclusive a ocorrência de atos de agressão e violência. Segundo Hornblas (2009), o uso de apelidos pejorativos pode gerar sofrimentos de origem psicológicas e reações intempestivas por parte dos alunos que são apelidados. Além disso, percebemos que os professores tentavam suprimir a prática do bullying que quase passava despercebida na escola apesar de queixas e reclamações dos alunos.

De forma bem específica e ilustrativa, o seminário, um dos momentos mais esperados e importantes, trabalhou a temática do bullying, suas consequências e formas e de prevenção, destacando-se os três personagens envolvidos: agressor, vítima e espectadores. Nesse momento, as diversas formas de bullying apresentadas por Silva (2010) foram abordadas, procurando-se identifica-las no deu dia a dia no ambiente 
escolar. Por fim, proporcionou-se aos escolares momentos para reflexão sobre seus atos, valorização da auto-estima com mensagens de otimismo e respeito, estimulando a identificação de comportamento amigáveis e saudáveis.

\section{Considerações finais}

A literatura científica sobre o bullying e a experiência obtida com a realização desse projeto demonstraram que essa temática ainda é pouco debatida nos espaços escolares devido aos vários "tabus" existentes sobre essa questão. Contudo, advoga-se que a mesma pode ser bem aceita entre os alunos se for abordada de forma lúdica e contínua, possibilitando melhor compreensão do tema e o fortalecimento de relações saudáveis entre os escolares. Dessa forma, iniciativas que tenham o bullying como objeto de intervenção são importantes para a construção de uma consciência individual e coletiva em ações de cidadania no convívio escolar.

Os resultados obtidos foram produtivos e gratificantes ao passo que contribuiu para a escola com importantes informações sobre a prevenção do bullying, de modo a fomentar outras futuras iniciativas. A troca de experiências e o diálogo entre alunos e tutores, também promoveu um grande aprendizado para todos os participantes mediante a conscientização em relação ao bullying, demostrando que o respeito ao próximo deve ser uma conduta a ser praticada por todos, não ignorando as peculiaridades físicas ou comportamentais, para a construção de um convívio melhor entre todos. ${ }^{1}$

\section{REFERÊNCIAS}

ARAÚJO, U. F. Temas transversais e a estratégia de projetos. São Paulo: Moderna, 2003.

BRASIL. Lei 13.185, de 06 de Novembro de 2015. Institui o Programa de Combate à Intimidação Sistemática (Bullying). Diário oficial da União, Brasília, 09 nov. 2015. Disponível

em: <http://www.planalto.gov.br/ccivil_03/_Ato20152018/2015/Lei/L13185.htm>. Acesso em: jan. 2016.

\footnotetext{
1 Agradecimentos ao Fundo Nacional de Desenvolvimento da Educação (FNDE) pela concessão das bolsas.
} À Escola Municipal Noé Fortes pelo apoio e colaboração para a execução do projeto de extensão. 
BRASIL. Lei 9.394, de 20 de dezembro de 1996. Lei de Diretrizes e Bases da Educação.

CALHAU, L. B. Bullying: o que você precisa saber: identificação, prevenção e repressão. 3 a ed. Niterói: Impetus, 2011.

CHAUÍ, M. Convite à Filosofia. São Paulo: Ática, 2003.

FANTE, C. Bullying no ambiente escolar. Disponível em: $<$ http://inov.org.br/site/artigos/9.pdf>. Acesso em: jan. 2016.

FANTE, C. Fenômeno Bullying. Como prevenir a violência nas escolas e educar para a paz. Campinas: Editora Verus, 2004.

FREIRE, P. Pedagogia da autonomia: saberes necessários à prática educativa. São Paulo: Paz e terra, 1996.

FREIRE, P. Educação "bancária" e educação libertadora. In M. H. S. Patto (Org.). Introdução à psicologia escolar. 3. ed. São Paulo: Casa do Psicólogo, 1997. p. 61-78.

HORNBLAS, D. S. Bullying na escola. Como as crianças lidam e reagem diante de apelidos pejorativos. Dissertação de Mestrado. PUC-SP, 2009.

MARTÍNEZ, . M. A. Bullying: intimidación y maltrato entre el alumnado. Bilbao: SteeEilas, 2001.

ORGANIZAÇÃO DAS NAÇÕES UNIDAS. Declaração Universal dos Direitos Humanos. Adotada e proclamada pela Assembleia Geral das Nações Unidas (resolução 217 A III) em 10 de dezembro 1948.

PIAGET, J. Para onde vai a educação? Rio de Janeiro: Livraria José Olympio Editores, 1973.

SILVA, A. B. B. Bullying: cartilha 2010 - projeto justiça das escolas. 1. ed. Disponível em: <http://www.cnmp.mp.br/conteate10/pdfs/tema3_cartilha-bullying-cnj.pdf>. Acesso em: jan. 2016.

SILVA, A. B. B. Mentes perigosas nas escolas. Rio de Janeiro: Objetiva, 2010. 
Ações do Programa de Educação Tutorial (PET): Intervenções para prevenção do bullying

\section{Actions of the Tutorial Education Program} (PET): Interventions to prevent bullying

\begin{abstract}
The paper is an experience report of lived with students from a public school in Teresina, PI, to work the theme of bullying, its prevention, identification and consequences. The study was conducted using as a method to problem-based education of Paulo Freire. Despite the students perceive aggression practices, it was found that the subject is still little discussed, and several taboos. It was noted that educational interventions contributed to sensitize students and other stakeholders of the school to the adoption of healthy relations practices as a way of prevent violence and arouse the attention of participants to create ways to confront this problem.
\end{abstract}

Key-words: Bullying. School. Human Rights.

Original submetido em: 17 fev. 2017

Aceito para publicação em: 28 mar. 2017

\section{Acciones del Programa de Educación Tutorial (PET): Intervenciones para prevenir la intimidación}

Resumen: Los informes en papel la experiencia vivida con los estudiantes de una escuela pública de Teresina, PI, para trabajar el tema de la intimidación, su prevención, identificación y consecuencias. El estudio se llevó a cabo utilizando el método de la educación como problemática de Paulo Freire. A pesar de que los estudiantes perciben las prácticas asaltos sujetos rara vez se discute y hay varios tabúes. Las intervenciones educativas han contribuido a sensibilizar a los estudiantes y otros actores de la escuela a la adopción de prácticas de relaciones saludables con el fin de prevenir la violencia y despertaron la atención a la creación de formas para hacer frente a este problema.

Palavras clave: La intimidación. Escuela. Derechos humanos.

Sobre os autores:

Cecilia Maria Resende Gonçalves de Carvalho

Departamento de Nutrição, Universidade Federal do Piauí

Raul Santos Silva

Estudante do Curso de Direito, Universidade Federal do Piauí

\section{Dheyvid Fhelipe Correia Lima Pereira}

Estudante do Curso de Pedagogia, Bolsista Programa de Educação Tutorial, Universidade Federal do Piauí

\section{Kelciane Mendes da Silva}

Estudante do Curso de Pedagogia, Bolsista Programa de Educação Tutorial, Universidade Federal do Piauí 